\title{
Algunos problemas de interpretación de la religión Chané
}

Quelques problèmes d'interprétation de la religion Chané

Some problems in the interpretation of Chané religion

\section{Diego Villar}

\section{(2) OpenEdition}

\section{Journals}

Edición electrónica

URL: http://journals.openedition.org/bifea/3664

DOI: $10.4000 /$ bifea.3664

ISSN: 2076-5827

Editor

Institut Français d'Études Andines

Edición impresa

Fecha de publicación: 1 diciembre 2007

Paginación: 393-405

ISSN: 0303-7495

Referencia electrónica

Diego Villar, «Algunos problemas de interpretación de la religión Chané », Bulletin de l'Institut français d'études andines [En línea], 36 (3) | 2007, Publicado el 01 junio 2008, consultado el 03 diciembre 2020 URL : http://journals.openedition.org/bifea/3664 ; DOI : https://doi.org/10.4000/bifea.3664

\section{(c) (i) (9)}

Les contenus du Bulletin de l'Institut français d'études andines sont mis à disposition selon les termes de la licence Creative Commons Attribution - Pas d'Utilisation Commerciale - Pas de Modification 4.0 International. 


\title{
Algunos problemas de interpretación de la religión Chané
}

\author{
Diego Villar
}

\section{Resumen}

Se evalúa la pertinencia de algunas ideas clásicas en el estudio antropológico de las religiones para comprender la religión Chané. Para discutir dos cuestiones básicas — la posibilidad de traducción intercultural y el carácter situacional de los contextos de sentido- se examinan aspectos como la articulación del simbolismo con distintos aspectos de la estructura social; el problema de la ambigüedad simbólica; la coexistencia entre los aspectos pragmáticos y simbólicos de la acción; la idea de sacralidad como interdicción; la preeminencia de la ritualidad; el carácter de sistema de las creencias religiosas; las implicancias exegéticas, conceptuales y metafísicas del empleo misionero de nociones indígenas para traducir la idea cristiana de «alma»; $y$, finalmente, la integración selectiva de influencias culturales externas.

Palabras clave: chané, chiriguano, arawak, tupí-guaraní, chaco, religión, interpretación, simbolismo

\section{Quelques problèmes d'interprétation de la religion Chané}

\section{Résumé}

Pour comprendre la religion Chané, plusieurs des concepts classiques en anthropologie religieuse seront ici mis à l'épreuve. La discussion de deux questions essentielles - la viabilité d'une traduction interculturelle et le caractère situationnel des contextes de sens - repose sur l'examen des aspects suivants : I'articulation du symbolisme à différents aspects de la structure sociale; le problème de l'ambiguïté des symboles; la coexistence entre les aspects pragmatiques et symboliques de l'action ; l'idée de sacralité comme interdit ; la prééminence de la ritualité ; l'aspect systémique des croyances religieuses; les implications exégétiques, conceptuelles et métaphysiques de l'emploi par 
les missionnaires de notions indigènes pour traduire l'idée chrétienne d'«âme»; et, finalement, l'intégration sélective d'influences culturelles externes.

Mots clés : chané, chiriguano, arawak, tupí-guaraní, chaco, religion, interprétation, symbolisme

\title{
Some problems in the interpretation of Chané religion
}

\begin{abstract}
The relevance of some classical ideas of the anthropological study of religions for the understanding of Chané religion is examined. In order to examine two basic premises - the degree of possibility of intercultural translation and the relative character of contexts of meaning - several aspects are discussed: the relationships between symbolism and diverse features of social structure; the problem of symbolic ambivalence; the coexistence of pragmatic and symbolic dimensions of action; the idea of the sacred as interdiction; the preeminence of ritual; the systematic character of religious beliefs; the exegetical, conceptual and metaphysical implications of the missionary use of indigenous notions to translate the Christian idea of the «soul»; and the selective integration of foreign cultural influences.
\end{abstract}

Key words: chané, chiriguano, arawak, tupí-guaraní, chaco, religion, interpretation, symbolism

\section{INTRODUCCIÓN}

En las últimas décadas, el estudio de los sistemas cosmológicos de los pueblos de las tierras bajas de Sudamérica ha sido dominado por diversas teorías de inspiración estructuralista forjadas, en su gran mayoría, en el seno de la floreciente etnología amazonista. Siguiendo las huellas de la «apertura hacia el Otro» — postulada por Lévi-Strauss (1992)—, esta auténtica explosión de lo amazónico se ha visto ampliamente justificada por la vitalidad heurística, conceptual y metodológica que ha logrado inyectar en la discusión disciplinar (Taylor, 1996; Descola, 1998; Viveiros de Castro, 1998; Surrallés, 2003). En este contexto, las etnias de ascendencia tupí-guaraní se han visto particularmente beneficiadas por la atención disciplinar (Carneiro da Cunha \& Viveiros de Castro, 1985; Combès, 1991; Viveiros de Castro, 1992; Fausto, 2001, 2005). Entre ellas, también lo han sido muchas próximas histórica, geográfica y étnicamente a los actuales chiriguano y chané (Combès \& Saignes, 1991). Los chané son un grupo étnico de origen arawak que se estableció poco antes de la Conquista entre el Chaco occidental y las laderas orientales de los Andes bolivianos. Allí fueron conquistados y sometidos durante los siglos XVI y XVII por bandas tupí-guaraní que llegaban a la misma zona en busca del oro fabuloso de los Incas y de la legendaria «tierra sin mal». Del mestizaje entre ambas sociedades nació, ya en el ámbito chaqueño, el grupo que la literatura Ilamó «chiriguano» (Susnik, 1968; Saignes, 1990; Combès \& Saignes, 1991; Combès, 2005). Sin embargo, pese a que los actuales chané hablan un dialecto guaraní y comparten en gran medida la cultura de sus conquistadores, en el noroeste argentino y el sur de Bolivia algunos grupos han mantenido la independencia práctica y una conciencia clara de su diferencia étnica (Bossert \& Villar, 2004; Combès \& Villar, 2004). Más allá de su lejano origen amazónico, lo que importa destacar es que la ubicación de los chané en el área cultural chaqueña invita a pensar en términos de una cierta especificidad. En 
efecto, cuando se trata de interpretar la vida religiosa de los grupos étnicos chaqueños no siempre es posible aplicar mecánicamente las claves amazonistas de la predación —el canibalismo o la afinidad potencial-; pensamos, por ejemplo, en la excelente monografía de John Palmer sobre los wichí occidentales (Palmer, 2005)1. Aquí no pretendemos, en modo alguno, cuestionar la validez de las teorías amazonistas, sino simplemente plantear en qué medida otras propuestas clásicas de la antropología social — no necesariamente incompatibles con el paradigma amazónico pero definitivamente menos frecuentes en la bibliografía sobre tierras bajas- pueden complementarlas y resultar igualmente fructíferas a la hora de analizar los fenómenos religiosos. Para ello examinaremos algunas ideas que sugiere el estudio de la religiosidad Chané en sus rasgos más generales, a fin de discutir con cierto grado de abstracción la pertinencia de algunas perspectivas de análisis, herramientas conceptuales y modalidades metodológicas².

\section{ALGUNOS PROBLEMAS DE TRADUCCIÓN}

Si queremos comprender la religión Chané no tiene demasiado sentido fatigar las explicaciones universalistas que reducen las prácticas y representaciones a los elementos comunes de cualquier religión; esta óptica diluye el simbolismo en un catálogo de arquetipos, en el magma residual del sentimiento numinoso, en variaciones sobre el tema de la sacralidad. Mal que nos pese, no existe un mínimo común denominador que condense la diversidad de los fenómenos religiosos; lo que plantea, entonces, el problema de interpretar sistemas cosmológicos diferentes y, en particular, cómo hacerlo.

En efecto, una vez adoptado un punto de vista analítico que privilegia lo concreto, resta solucionar el viejo dilema de la interpretación de las creencias ajenas —aquello que los filósofos anglosajones denominaron the problem of other minds-. En el caso Chané, podemos comenzar con la fuerte impresión que se trata de una religión de contextos y de circunstancias (Lienhardt, 1985; Gellner, 1998). La articulación del simbolismo con distintos aspectos de la estructura social — pensemos en la división sexual del trabajo, la uxorilocalidad o la organización política- opone, por ejemplo, el eje semántico de la comunidad, lo femenino, lo doméstico y lo interior con el eje del monte, lo masculino, lo público y lo exterior. No se trata de sugerir una conceptualización férrea de la totalidad de la experiencia mediante una clasificación dualista; sin embargo, esto no quiere decir que estas oposiciones no operen en registros específicos con sentidos situacionales y relativos: el espacio de cultivo, así, puede concebirse como un elemento mediador entre los ámbitos del monte y la comunidad, ya que es «social» en relación con el primero y «natural» en contraposición con el segundo (Needham, 1973).

En consecuencia, cuando examinamos afirmaciones del tipo «los chané creen tal cosa», debemos ejercitar un constante recelo exegético y desmentir de antemano la ilusión de una credulidad uniforme y estricta. A la vez, debemos evitar las trampas que nuestro propio lenguaje impone a la labor de traducción (Needham, 1972). ¿En qué medida es lícito atribuir a los chané la creencia que la máscara ritual «transforma» a su portador en un ancestro, o que temen a los zorros porque «encarnan» los espíritus de sus antepasados? ¿En qué sentido puede decirse — si es que puede decirse — que el daño de la brujería tiene un valor

\footnotetext{
1 A modo de excepción, podríamos mencionar los trabajos de Combès \& Saignes (1991) y Sterpin (1993).

2 Para un estudio más detallado de diversos aspectos de la ideología religiosa chané, cf. Bossert, 2002; Bossert \& Villar; 2001; 2004; 2006; Villar, 2005; 2006. Para una perspectiva etnohistórica y etnográfica más general sobre la vida social de los chané y chiriguano, cf. Combès, 2005; Combès \& Villar, 2004; Lowrey, 2003.
} 
éticamente negativo? ¿Es apropiado hablar del «mal» cuando la conducta es involuntaria? Las aporías implícitas en categorías como «deidad», «alma», «mal» o «posesión» surgen, aquí, en toda su dimensión. Dada la dialéctica de opacidad y revelación del símbolo, la imaginación humana solo capta destellos parciales y fragmentarios de las potencias religiosas. El dueño del monte, custodio de la geografía en la que viven los chané, se les manifiesta a través de un aroma, la oscuridad o una serpiente, pero a la vez es ocultado por ellos (Bossert \& Villar, 2001). La relación con las potencias está inevitablemente mediada por los símbolos que encarnan su accionar a ojos de los hombres, pero a la vez estos saben que su voluntad — como la intención ambivalente de los muertos o la perfidia del brujo - desborda siempre a sus manifestaciones particulares y no puede confundirse con ninguna de ellas.

Las mismas manifestaciones concretas se revelan problemáticas. Los pájaros agoreros no son temidos en sí mismos, en todos los momentos y en todas las circunstancias; de hecho, los chané hablan perfectamente de ellos en un sentido taxonómico o biológico sin sentir temor alguno. Si bien es cierto que en el plano ideológico el zorro puede ser considerado un mal augurio - por ser acaso la figuración más corriente del alma de los muertos-, se lo trata sin problemas en los ámbitos de la caza, la toponimia o la mitología. Los seres cosmológicos, en suma, se resisten a encajar en una lógica que contrapone nítidamente la unidad y la multiplicidad. Algunas veces los vientos y los remolinos son, simplemente, vientos y remolinos; otras veces son cifras de presencias inauspiciosas; en otras ocasiones, por fin, no son interpretados como signos, sino como esas mismas presencias. Según el registro moralista, narrativo o pragmático que se enfatice, el zorro puede ser un animal, un espíritu o la astucia irresponsable del trickster - pero lo más frecuente es que sea todas esas cosas a la vez-. De la misma forma, el dueño del monte suele ser primero una sensación de soledad o de desamparo; luego un aroma penetrante o un ventarrón; luego una serpiente y momentos después un personaje antropomorfo; y, la mayoría de las veces, todos ellos al mismo tiempo. Cuando los chané traducen esta complejidad al castellano parecen incorregiblemente supersticiosos, ya que tendemos a pensar en un hombre, el viento o la serpiente como seres necesariamente distintos. A lo sumo intentamos trascender el nivel literal del enunciado interpretándolo como una asociación metafórica, como una alegoría. No se nos ocurre que puedan existir formas múltiples de ver a un mismo ser pues nuestras propias categorías nos obligan a discriminar si la criatura es «realmente» un hombre o «realmente» una serpiente (Lienhardt, 1954).

En este punto tal vez sea provechoso invertir por un momento el sentido de la traducción. Los chané evangelizados por los misioneros católicos muchas veces asisten a misa y toman la comunión; sin embargo, como en el caso del bautismo, interpretan la eucaristía en función de una lógica de acumulación de fuerzas y esperan sentir un cambio físico perceptible tras ella. Ahora bien, si quisiéramos explicarles las sutilezas teológicas implícitas en el rito, lo menos que deberíamos hacer es reflejar las diferentes actitudes que nuestra propia cultura permite frente al mismo. En un extremo, los creyentes asumen a pie juntillas el dogma de la transubstanciación; es decir, ingieren literalmente el cuerpo y la sangre de Cristo. En el otro, el ateo recalcitrante asiste a la mera ingestión de un trozo de pan. Pero entre ambos polos pulula una infinidad de interpretaciones más matizadas, ni completamente incrédulas ni completamente canónicas, que tras el símbolo atisban una metáfora, una parábola, una analogía o una conmemoración. Sería simplista plantear una elección tajante entre la hostia como el cuerpo de Cristo o la hostia como un mero trozo de pan. Igualmente simplista sería preguntar a los chané si el enmascarado es «realmente» un actor que simula o «realmente» un antepasado que se apodera del cuerpo del danzante. De hecho encontramos algunos informantes que piensan lo primero y otros lo segundo; pero lo desconcertante, lo que llama a la reflexión, es que la mayoría piensa lo primero en algunos contextos y lo segundo 
en otros. Nuestro propio lenguaje, con su ontología implícita, forja entonces nuestra perplejidad al forzar la alternativa entre la interpretación figurativa y la literal. Hacer justicia al pensamiento Chané, por el contrario, implica respetar zonas grises, matices, vías intermedias, sinuosas, ambiguas, que no se limitan a una dicotomía entre lo literal y lo metafórico - así, el sentido de la asociación entre máscaras y ancestros reposa entre ambos polos sin encajar del todo en ninguno- . De la misma forma, decir que la experiencia de los muertos varía según se trate de las comunidades más o menos evangelizadas es una obviedad; tal vez sea menos evidente suponer que esta experiencia muta de persona a persona; pero lo importante es que, aun para un mismo individuo, varían las circunstancias a través de las cuales se relaciona en distintos momentos con las almas de los antepasados. La relación festiva con los muertos — signada por el respeto, la broma y el parentescoinvierte la relación pavorosa que experimenta durante el resto del año. Como el zorro, la máscara no es un símbolo per se de los muertos, sino tan solo dentro del contexto del rito porque éste funciona como una medida del paso del tiempo disparando la reflexión acerca de la finitud (Bossert \& Villar, 2006). Aun así, el éxito de las creencias es indisociable de contextos de sentido más amplios, plasmados en otras representaciones y prácticas que engloban al rito y contribuyen a reforzar su eficacia como la alteración consciente de la identidad, la representación y el simulacro, la escatología, la exégesis de la prédica misionera, los ritos y creencias de otras etnias vecinas (Lévi-Strauss, 1994), el vértigo de la danza y la borrachera ritual o la misma obtención de aquellas materias primas con las cuales se confecciona la parafernalia ritual (Mauss \& Hubert, 1946; Mauss, 1991).

La exuberancia que anida tras la eficacia simbólica no debería conducirnos a sobrestimar la solemnidad de la racionalidad cosmológica. Los chané son perfectamente conscientes del carácter situacional de su simbolismo. La misma brujería que los daña y los lleva a la muerte resulta inútil frente al etnógrafo; del mismo modo, saben bien cuándo una afección debe ser atendida por la medicina oficial y cuándo es patrimonio del shamán. La acción simbólica se combina con el saber técnico en configuraciones variables de pensamiento y experiencia. Las prácticas positivas y negativas del monte, por ejemplo, muchas veces son explicadas a partir de consideraciones pragmáticas: se deben talar responsablemente los árboles y no desperdiciarlos, hay que cazar y pescar con moderación (Bossert \& Villar, 2001). Pero más allá de los pretextos de la razón práctica, infringir esas reglas implica un castigo ajeno a cualquier consideración pragmática. No se trata - o no se trata solamente- de un acto racionalmente inconveniente, sino de una infracción que más tarde o más temprano será penada mediante accidentes, pérdidas del sentido de orientación, enfermedades misteriosas, la locura o aun la muerte. Lo más justo, lo más fiel al pensamiento Chané sería decir que en el ciclo de prestaciones entre los hombres y las potencias, aquello que nosotros llamaríamos «azar» no indica la fortuna o la contingencia, sino una relación de necesidad, una causa efectiva, el estado del vínculo de cada individuo con los dueños reales de las cosas. No extraña, en estas circunstancias, que el léxico Chané carezca de una traducción adecuada para nuestra categoría de «suerte». La eficacia del cazador o el artesano no se asocia únicamente con su talento personal, sino también con el modo en que aprende a administrar su dependencia frente a fuerzas que lo superan. Sin embargo, simultáneamente, cuando un cazador dirige una ofrenda al dueño de los animales para tener éxito no está exento de moverse con sigilo, adiestrar a sus perros, conocer los hábitos de las presas, apuntar bien su arma o elegir los mejores lugares para emboscarse. Los chané saben que el trato con el dueño no hace que un mal cazador consiga presas; en todo caso, explica por qué un cazador avezado las consigue a veces y otras no. No quedan satisfechos atribuyendo el éxito o el fracaso a un accidente — desde este punto de vista, su razonamiento parece más inquisitivo que el nuestro- . Se preguntan por qué le sucede un evento determinado a 
un hombre en particular, en un espacio y un momento particulares. Nuestra lógica del azar y la coincidencia no responde a la desgracia; los chané, en cambio, optan por un esquema explicativo que les ofrece la oportunidad de actuar (Evans-Pritchard, 1976).

Las tensiones de la exégesis no acaban allí. El shamanismo o las creencias relativas a la escatología son auténticos campos de interacción simbólica entre los sistemas de creencia de los chané, otros indígenas, misioneros y criollos (Chaumeil, 1998; Gruzinski, 2000). Los infortunios en la traducción misionera de la idea de «alma» son paradigmáticos de los procesos de asimilación, rechazo o reapropiación de las disciplinas intelectuales impuestas desde el exterior3. Cuando preguntamos a los chané por sus diferentes «almas», no deberíamos olvidar que los mismos términos, mediante los cuales lo hacemos, significan literalmente «vida» (tekove) e «imagen» o «sombra» $(i$ a). En consecuencia, sugerir que una persona tenga diferentes «imágenes» $\mathrm{O}$ «vidas» no tiene demasiado sentido en su lengua, por más que la catequesis los haya acostumbrado a la glosa animista. Inversamente, los mismos misioneros que traducen esas nociones como «alma» jamás aceptarían que el tekove y el $i$ a son, ambos, almas. La presunta equivalencia entre las nociones indígenas y cristianas tiene claras implicancias conceptuales y metafísicas. Primero, supone la personificación espiritualizada de una entidad cuyo destino es regido por la vinculación con un Dios también personalizado y único. Segundo, esta relación es concebida prioritariamente en términos morales y éticos. Tercero, este énfasis moral, sumado a la concepción del alma como esencia indestructible de la persona, vuelve lógicamente necesaria una formalización de sus posibles destinos de ultratumba; en otras palabras, la sistematización artificiosa del imaginario escatológico. Finalmente, cuando hablamos de problemas de traducción, podríamos hacerlo en un sentido todavía más literal. Indígenas y misioneros circulan, interpretan y oponen sus ideas en lenguas que admiten diferentes grados de abstracción. Los sustantivos que designan en guaraní a los componentes de la persona solo se enuncian en posesivo: cherecove, chea, chere. Entidades como la vitalidad, el alma o nombre personal son siempre «de alguien» y casi no tienen sentido consideradas en abstracto; de ser necesario, se las designa empleando la tercera persona del singular (Bossert \& Villar, 2004). Cuando se utiliza la palabra chea como glosa de la idea de «alma», por ende, el uso castellano inyecta un grado de abstracción inexistente en el concepto original.

Pero tal vez la consecuencia más importante sea que la idea de «alma», con su énfasis en la autonomía individual, implica un término unitario que remite a la voluntad, la subjetividad y la autoconciencia. La insistencia misionera en la familia nuclear, el bautismo, la necesidad de individualización mediante el nombre, la inserción indígena como fuerza de trabajo en las economías regionales, son prácticas que desarticulan aquellas redes de dependencias y jerarquías en las cuales la noción de «individuo» en sentido occidental quedaba tradicionalmente diluida. En el plano espiritual la introspección, la valoración del sí mismo, el libre albedrío, la responsabilidad para con Dios —en suma, la dinámica del pecado, la expiación redentora y la salvación (Hertz, 1996) —, plantean la necesidad (hasta entonces inédita) de un «alma» que traba una relación personal con la divinidad; o, en otras palabras, la concepción personalizada de Dios requiere su contraparte en una conciencia individual. Pero los chané viven tranquilamente sin un concepto de «mente» que almacena todas las experiencias del yo. En este sentido sería inapropiado concebir el $i$ a «dentro» del cuerpo operando como la contraparte espiritualizada de las funciones físicas, corporales

\footnotetext{
${ }^{3}$ Véase, por ejemplo, la traducción de distintos conceptos chiriguanos en el trabajo de los frailes Bernardino de Nino (1912), Doroteo Giannecchini (1996), Doroteo Giannecchini et al. (1916) y Santiago de León (1998) — problemas cuyo influjo se advierte también en diccionarios modernos como el de Dietrich (1986)—. Para un panorama más amplio sobre el tema entre los chané contemporáneos, cf. Villar, 2006.
} 
o biológicas de la persona —el «fantasma en la máquina» de Ryle (1963)—. El dualismo ficticio que deriva de esta concepción no logra mas que evocar la conjunción torpe entre un espectro y un autómata. Para los chané, las imágenes oníricas y mnemónicas no constituyen procesos «mentales» en nuestro sentido - actos silenciosos y privados que tienen lugar en el interior de la persona-. El esclarecimiento de recuerdos y sueños no obedece a la introspección ni a la voluntad, sino a un encuentro entre imágenes, reflejos o sombras cuya precondición es el contacto con el prójimo; estas imágenes pertenecen a la esfera pública, e incluso pueden ser percibidas por los demás (Lienhardt, 1989; Palmer, 2005).

\section{SACRALIDAD Y PRAXIS}

Atender la especificidad de la religión Chané implica rastrear el juego específico de asociaciones que la gente realiza entre los fenómenos religiosos y los seculares; pero también, y fundamentalmente, entre los fenómenos religiosos en la acepción de nuestro sentido común y los que pueden considerarse «religiosos» en un sentido durkheimiano. Más allá de las interpretaciones ocasionales, fatalmente provisorias, si hay algo válido en el proceso de la investigación debería ser el juego de conexiones que los mismos creyentes establecen entre su conducta religiosa y una serie de contextos culturales diversos. Para no quedar estancados en el terreno de las definiciones generales, aquí retendremos únicamente la idea que lo sagrado es una categoría formal de pensamiento que refleja las diferencias de potencial, el valor relativo de las cosas. En el fondo, lo único que puede decirse sobre lo sagrado es que se opone a lo profano —es lo que está separado, lo restricto, aquello ante lo cual el hombre no puede comportarse libremente ni con impunidad (Durkheim, 1995)—. Más que una cualidad positiva, se trata de una vacilación que retiene, un escrúpulo que impide. Para el chané, el acatamiento de las prescripciones rituales condiciona la experiencia cotidiana sin exteriorizar una fe preexistente. La corrección formularia de la conducta, que hace pensar en el antiguo sentido latino de la palabra «rito», precede en todos los casos al trazado de la representación cosmológica (Granet, 1959). Los tabúes y las interdicciones que regulan la relación entre el hombre y el monte, por ejemplo, materializan buena parte de las ideas relativas al peligro, la ambigüedad y la transgresión, confinándolas en ámbitos concretos y reglamentando la acción apropiada frente a ellas. El sistema de interdicciones enseña al individuo a qué debe temer (Steiner, 1999). Los chané no razonan como si la intrusión de la mujer en el monte fuera peligrosa, incorrecta o inmoral en sí misma, y por tanto castigada; a la inversa, como los poderes sancionan el contagio femenino desatando desgracias sobre ellos, lo juzgan negativamente.

Esta preeminencia de la ritualidad tiene una dimensión fuertemente pragmática. Cuando los chané enuncian la máxima cosmológica opaite iya — «todo tiene dueño»- no elucubran una doctrina sobre el mundo, sino que expresan un vínculo que da por sentado al percibir diariamente sus efectos. La frase no debería entenderse como «hay dueños de todo», sino como la conciencia de una presencia protectora o peligrosa, pero en todo caso ubicua y en última instancia incomprensible (Evans-Pritchard, 1980). Cuando preguntamos por qué el dueño ha enfermado a tal persona o le ha dado los secretos a otra, la respuesta que remite a su designio ofrece un grado de exégesis más allá del que cualquier cuestionamiento deja de tener sentido. Podría decirse que los chané no «creen» en los seres del monte; simplemente los aceptan e interactúan con ellos. Lo que llamamos «creencia» no remite a una doctrina ontológica, sino a grados diversos de expectativa; a la convicción que aquél en quien se deposita la confianza no fallará y la retribuirá como apoyo o protección, ya que en última instancia se trata de una operación de intercambio (Benveniste, 1983). Nuestra encuesta presupone que estos seres se «materializan» en su contacto con la gente pero a la vez que, 
independientemente de estos encuentros específicos, tienen una existencia tal como la que le atribuiría la misma carga semántica de nuestro lenguaje. En general esto no tiene sentido para el chané común, a quien poco importa la teoría sobre la existencia «en sí» de las potencias desligada de las relaciones — siempre inestables, siempre diversas- que mantiene con ellas (Lienhardt, 1985). Se vincula con los poderes sin tomarse el trabajo de probarlos, al menos en la misma medida en que nosotros somos capaces de no creer en ellos sin molestarnos en esgrimir su refutación.

El análisis del imaginario religioso supone entonces el examen previo de diversos modos de acción social como la liturgia o la moral, pero también las actividades de subsistencia, la ideología política o las clasificaciones interétnicas —en otras palabras, los diversos códigos que regulan la conducta cotidiana- La religión Chané se afianza como un sistema de acción concreta, un pensamiento preocupado por el aquí y el ahora. Esta materialidad hace que su simbolismo no se condense en ortodoxias rígidas, arcanos esotéricos o doctrinas dogmáticas; por el contrario, sus reflejos parciales deben captarse en el juego de perspectivas recíprocas de hombres y mujeres, niños, adultos y ancianos, los distintos especialistas religiosos y sus diversas clientelas, las aristocracias cacicales y las personas comunes, los vivos y los muertos, los hombres y los animales, los chané y sus vecinos chiriguano, chaqueños y criollos.

Ahora bien. La lógica concreta del sistema no impide que funcione como un modo de pensamiento. De hecho implica una manera bien determinada de clasificar, coordinar, agrupar y oponer los hechos de la experiencia; una clasificación valorativa que conceptualiza el universo distinguiendo múltiples tipos de poderes, influencias, causalidades y soberanías. Si tuviéramos que resumir su ideología en una sola sentencia, deberíamos decir que es un pensamiento que se regodea en la ambigüedad. En efecto, no establece distinciones tajantes entre el ámbito interior del creyente y el universo externo, entre la vigilia y el sueño, entre lo literal y lo metafórico, entre la unidad y la multiplicidad, entre las jerarquías del mundo social y las leyes del universo físico. Esta fluidez le brinda una capacidad enorme de articulación de la experiencia. Frente al ideal racionalista de las ideas claras y precisas, explota la polisemia y neutraliza los confines entre los distintos sectores de lo real. Expresa las armonías y tensiones de la interconexión de las realidades personales, sociales, naturales y sobrenaturales en un caleidoscopio de ecos y refracciones múltiples. Propone un lenguaje para pensar la realidad en su conjunto, sin resignarse a dividirla en áreas ni a segmentar su comprensión. Integra al individuo en grupos sociales, con sus reglas, sus clasificaciones, sus jerarquías; luego liga a esos mismos grupos con el orden de la naturaleza; luego asocia el curso de la naturaleza con un orden sagrado; por último, conforma un lenguaje común mediante el cual las experiencias individuales, sociales y naturales pueden traducirse las unas en las otras mediante los mismos términos. El juego de analogías entre la representación de las relaciones interétnicas y las andanzas de los personajes míticos, por citar un caso, revela que la imaginación simbólica no resuelve los problemas dando respuestas parciales a cada uno de ellos, sino mostrando que son homólogos entre sí (Villar, 2005). Cada aspecto de la experiencia, según el contexto, es activado y puesto en contacto con la totalidad del universo — sintetizando, la religión Chané se nos presenta como un hecho social total-.

\section{HACIA UNA SOCIOLOGÍA DE LA RELIGIÓN CHANÉ}

La lectura en clave sociológica de una ideología religiosa no implica en modo alguno la tesis de una proyección mecánica del orden social. La religión Chané es un sistema articulado de ideas y prácticas con derecho propio. Deben describirse sus estructuras, sus mecanismos, sus equilibrios constitutivos tal como se definen discursiva, pragmática 
y simbólicamente en diversos contextos de sentido. Sin embargo, es imposible estudiar los hechos religiosos como si constituyeran un mundo independiente de la vida social y material de quienes se adhieren a ellos. Las religiones — cualesquiera que sean- no funcionan en el vacío. Todo indica que la cosmología Chané puede entenderse como la trama de las relaciones entre el creyente y sus diversos prójimos - los seres del monte, los animales, los muertos, la gente propia y extraña (Viveiros de Castro, 1992)—. Las marcas de lo social impregnan lo cotidiano: los ciclos de reciprocidad, la clasificación del tiempo y del espacio, la concepción de la persona, el protocolo del monte, los cauces en que circulan las acusaciones y sospechas shamánicas, los mecanismos de articulación del imaginario taxonómico o aun la narrativa oral y la memoria histórica. La lógica simbólica emplea los mismos ejes, oposiciones y criterios que detectamos en la organización de los hombres. El monte - explícitamente contrapuesto con la sociabilidad de la aldea - se presenta, por ejemplo, como un cuadro indómito saturado de susurros, signos y presencias. Se trata de un universo incierto en el cual los animales, las plantas y aquellos seres como los muertos, el arco iris o los dueños de las cosas — cuya voluntad es virtualmente indescifrable — son percibidos, sin embargo, como sujetos sociales dotados en mayor o menor medida de una sociabilidad parangonable con la humana. Más allá de sus figuraciones concretas, todos estos poderes tienen sus propias reglas y sus propias jerarquías, concebidas en simetría con las instituciones sociales. Como se proyectan la voluntad, la intencionalidad y las regulaciones humanas, es inevitable que la «naturaleza» sea leída en la clave de un orden signado por la lógica de la reciprocidad, la propiedad, la prodigalidad, la consanguinidad, la alianza matrimonial y política (Durkheim \& Mauss, 1996). Como el espacio es organizado en función de ideas de valor que se atribuyen a cada una de las distintas regiones, el conocimiento del monte no puede conformar un registro abstracto de datos espaciales, biológicos o geográficos, sino que pone en escena una percepción cultural de la realidad, una auténtica cartografía conceptual.

Si las relaciones entre los diversos entes del universo se conciben en la clave del parentesco real o ficticio, los criterios de propiedad y las redes de reciprocidad, la religión Chané no lo refleja constituyendo un «panteón» en el sentido clásico. Su funcionamiento plástico, maleable e integrador supone la coexistencia de potencias e influjos de diversas procedencias, cuyas jurisdicciones y competencias suelen superponerse. Dibuja una cosmología signada por la división de poderes, carente de una autoridad centralizada y omnisciente. De allí deriva una tendencia natural hacia la incertidumbre: en parte porque el actor no alcanza a vislumbrar quién es responsable de cada acción, y en parte también por la ambigüedad simbólica que rodea a todas las potencias. Este pluralismo alimenta las rivalidades entre las fuerzas sagradas, y configura los contornos de un cosmos ordenado pero a la vez desgarrado por contradicciones, tensiones y conflictos de prerrogativas; una arquitectura de lo real sustentada sobre equilibrios delicados entre tendencias opuestas y armonías inestables.

Este dinamismo no atenta contra la idea que la religión Chané configure un sistema. Su funcionamiento no puede ser explicado más que atendiendo a las relaciones mutuas de sus elementos — es decir, a su carácter de totalidad articulada (Vernant, 1994)—. Metodológicamente esto implica que cada figura, cada idea, cada noción carece de una esencia propia y no puede definirse en sí misma: cada término se define por la red de relaciones recíprocas que lo une y lo distingue de los demás elementos que componen el conjunto. Es imposible comprender al shamán sin el brujo, a los muertos sin los vivos, a los varones sin las mujeres, a un chané sin un chiriguano. Es inútil analizar la actitud hacia el alma de un ancestro, o hacia un brujo, si no se la restituye en el conjunto mayor de relaciones que durante el ciclo anual se mantienen con las diversas potencias. De la misma 
manera, la comprensión profunda de la mítica animal requiere su puesta en relación con la humanidad propia y ajena, afines y consanguíneos, parientes y enemigos, indígenas y blancos. El entramado de asociaciones posibles no tiene fin. No basta entonces con un catálogo de motivos míticos, instancias rituales o divinidades, sino que se impone el análisis de los modos en los cuales las diversas potencias se agrupan, oponen y distinguen: solo así surgen los rasgos pertinentes para la imaginación simbólica.

La lectura sociológica de la religión Chané, por último, revela que se trata de un sistema de creencia que lleva inscriptas las marcas múltiples de sus interacciones históricas. La religión Chané, en una palabra, es tan compleja como su identidad étnica. Los chané padecieron, en primer lugar, la adaptación de su antiguo sustrato cultural amazónico al contexto chaqueño; en segundo lugar, la relación simbiótica con la idiosincrasia «guaranizante» de los chiriguano; en tercer lugar, los vínculos — pacíficos o bélicoscon otros grupos étnicos andinos y chaqueños; y, por último, los múltiples lazos con los diversos representantes de la sociedad criolla — patrones, hacendados, empresas, militares y misioneros4-. Se advierte así la plasticidad de una cosmovisión que integró selectivamente, en diferentes épocas, influencias tan dispares como la lengua guaraní, las prácticas arawak de enmascaramiento ritual, el shamanismo de los pueblos chaqueños, ciertas instituciones andinas y el folklore criollo. No extraña, tampoco, que esta síntesis híbrida configure un mosaico abigarrado que no se compromete con ninguna pureza teológica. Encontramos respaldo para esta lectura en la adopción de las teodiceas cristianas5. No se trata, o no se trata solamente, de un duelo de traducciones. La absorción del legado misionero - con sus cuadros institucionales, su atractivo económico y social, su coherencia interna, su fuerza de persuasión, su capacidad para construir ortodoxias - debe ponerse en relación con los cambios en la vida social de los creyentes. La colonización catequística no fue únicamente una contienda ideológica que opuso baterías de símbolos, amuletos y doctrinas. La guerra de imágenes fue precedida por la desarticulación de las redes tradicionales de organización social y alianza matrimonial: las confederaciones supralocales, la poliginia, el avunculado, el matrimonio entre primos, el levirato, el sororato y la familia extensa desaparecieron en detrimento de una exogamia planteada a partir del patronímico, el ideal de «comunidad» y la familia nuclear como interlocutor privilegiado de la vida parroquial. Sabemos también que el proyecto misionero modeló un individuo con «alma», «conciencia» y «mente», preferentemente alfabetizado, desligado de los circuitos tradicionales de intercambios, dependencias y jerarquías, inclinado hacia el trabajo, la superación personal y la responsabilidad, la ética cristiana y el espíritu del individualismo.

Pero no hay que temer demasiado. Si bien es cierto que las creencias y las prácticas cambiaron porque cambió la gente que se adhería a ellas, también lo es que el cristianismo Chané sigue siendo más Chané que cristiano. Develar la persistencia notable de la fluidez de los contextos de sentido, la vigencia de la ritualidad, la ambivalencia simbólica o la continua capacidad de integración selectiva de las influencias externas hace suponer que la religión Chané, como todas, está destinada a cambiar más que a desaparecer. Solo resta entonces saber cómo inteligir su realidad. Cuando pensamos en la situación particular de

${ }^{4}$ Sobre la absorción de diversas influencias culturales entre los chané y chiriguano en distintos períodos históricos, véase Nordenskiöld, 2002; Métraux, 1930, 1932; Renard-Casevitz et al., 1986; Combès \& Saignes, 1991; Lowrey, 2003; Combès, 2005; Combès \& Villar, 2004.

${ }^{5}$ Para una hipótesis sugestiva sobre la asimilación de elementos religiosos foráneos entre los guaraníes, véase Fausto, 2005. La absorción «caníbal» o «predatoria» de influencias ajenas ha sido explotada a fondo por los estudios amazonistas, e incluso elevada al rango de atributo definitorio de las cosmologías tupí-guaraní (Carneiro da Cunha \& Viveiros de Castro, 1985; Viveiros de Castro, 1992, 1998; Fausto, 2001). 
Algunos problemas de interpretación de la religión chané

religiones indígenas sometidas desde hace tiempo a intensos procesos de cambio, todo invita a pensar que solo queda la traducción, y que la traducción es imposible. El aforismo no celebra la apoteosis del solipsismo, sino que simplemente condena a quienes creemos que la antropología es una labor de traducción a una meta acotada pero acaso posible: una exégesis eternamente perfectible que aspira a grados cada vez mayores de inteligibilidad.

\section{Referencias citadas}

BENVENISTE, É., 1983 - Vocabulario de las instituciones indoeuropeas, 461 p.; Madrid: Taurus.

BOSSERT, F., 2002 - Algunas creencias y prácticas chané en torno de los muertos, Scripta Ethnologica, 22: 49-58; Buenos Aires.

BOSSERT, F. \& VILLAR, D., 2001 - Tres dimensiones de la máscara ritual chané. Anthropos, 96 (1): 59-72; Sankt Augustin (Alemania).

BOSSERT, F. \& VILLAR, D., 2004 - La onomástica chané en clave etnográfica y comparativa. Acta Americana, 12 (1): 49-78; Uppsala, Suecia.

BOSSERT, F. \& VILLAR, D., 2006 - Un problema de simbolismo. Las máscaras y los muertos entre los chané. In: Simbolismo, ritual y performance (G. Wilde \& P. Schamber, eds.): 59-82; Buenos Aires: SB.

CARNEIRO DA CUNHA, M. \& VIVEIROS DE CASTRO, E., 1985 - Venganza y temporalidad entre los Tupinamba. Journal de la Societé de Américanistes, 71: 191-208; París.

CHAUMEIL, J.-P., 1998 - Ver, saber, poder. Chamanismo de los yagua de la Amazonía Peruana, 361 p.; Lima: IFEA-CAAAP-CAEA.

COMBÈS, I., 1991 - La Tragédie cannibale chez les anciens Tupi-Guarani, 276 p.; París: PUF.

COMBÈS, I., 2005 - Etno-historias del Isoso. Chané y chiriguanos en el Chaco boliviano (siglos XVI a XX), 396 p.; La Paz: IFEA-PIEB.

COMBÈS, I. \& SAIGNES, T., 1991 - Alter Ego. Naissance de l'identité chiriguano, 152 p.; París: EHESS. Cahiers de l'Homme.

COMBÈS, I. \& VILLAR, D., 2004 - Aristocracias chané. «Casas〉 en el Chaco argentino y boliviano. Journal de la Société des Américanistes, 90 (2): 63-102; París.

DE NINO, B., 1912 - Etnografía chiriguana, 332 p.; La Paz: Tipografía Comercial de Ismael Argote.

DESCOLA, P., 1998 - Estrutura ou sentimento: a relação com o animal na Amazônia. Mana, 4 (1): 23-45; Río de Janeiro.

DIETRICH, W., 1986 - El idioma chiriguano: Gramática, textos, vocabulario, 356 p.; Madrid: Ediciones Cultura Hispánica.

DURKHEIM, É., 1995 - Las formas elementales de la vida religiosa, 423 p.; México: Diálogo Abierto.

DURKHEIM, É. \& MAUSS, M., 1996 - Sobre algunas formas primitivas de clasificación. In: Clasificaciones primitivas (y otros ensayos de antropología positiva): 23-104; Ariel: Barcelona.

EVANS-PRITCHARD, E., 1976 - Brujería, magia y oráculos entre los azande, 491 p.; Barcelona: Anagrama.

EVANS-PRITCHARD, E., 1980 - La religión nuer, 391 p.; Madrid: Taurus. 
FAUSTO, C., 2001 - Inimigos Fiéis. Historia, guerra e xamanismo na Amazônia, 587 p.; San Pablo: EDUSP.

FAUSTO, C., 2005 - Se deus fosse jaguar: canibalismo e cristianismo entre os guarani (séculos XVI-XX). Mana, 11 (2): 385-418; Río de Janeiro.

GELLNER, E., 1998 - Language and Solitude. Wittgenstein, Malinowski and the Habsburg Dilemma, 209 p.; Cambridge: Cambridge University Press.

GIANNECCHINI, D., 1996 - Historia natural, etnografía, geografía, lingüística del Chaco boliviano, 459 p.; Tarija: FIS, Centro Eclesial de Documentación.

GIANNECCHINI, D., ROMANO, S. \& CATTUNAR, H., 1916 - Diccionario ChiriguanoEspañol y Español-Chiriguano, 256 p.; Tarija: Publicación de la Orden Franciscana.

GRANET, M., 1959 - El pensamiento chino, 429 p.; México: Uteha.

GRUZINSKI, S., 2000 - La colonización de lo imaginario. Sociedades indígenas y occidentalización en el México Español. Siglos XVI-XVIII, 310 p.; México: Fondo de Cultura Económica.

HERTZ, R., 1996 - Sin and Expiation in Primitive Societies, 136 p.; Oxford: British Centre for Durkheimian Studies.

LÉVI-STRAUSS, C., 1992 - Historia de lince, 345 p.; Barcelona: Anagrama.

LÉVI-STRAUSS, C., 1994 - Antropología estructural, 428 p.; Buenos Aires: Altaya.

LIENHARDT, G., 1954 - Modes of thought. In: The Institutions of Primitive Society (E. E. Evans-Pritchard, ed.): 95-107; Oxford: Basil Blackwell.

LIENHARDT, G., 1985 - Divinidad y experiencia. La religión de los dinkas, 317 p.; Madrid: Akal.

LIENHARDT, G., 1989 - Self: Public, Private: Some African representations. In: The Category of the Person. Anthropology, Philosophy, History (M. Carrithers, S. Collins, \& S. Lukes, eds.): 141-155; Cambridge: Cambridge University Press.

LOWREY, K., 2003 - Enchanted Ecology: Magic, Science and Nature in the Bolivian Chaco. Doctoral Dissertation, 383 p.; Chicago: University of Chicago.

MAUSS, M., 1991 - Sociología y Antropología, 432 p.; Madrid: Tecnos.

MAUSS, M. \& HUBERT, H., 1946 - Magia y sacrificio en la historia de las religiones, 336 p.; Buenos Aires: Lautaro.

MÉTRAUX, A., 1930 - Études sur la civilisation des indiens chiriguano. Revista del Instituto de Etnología de la Universidad de Tucumán, 1: 295-493; Tucumán.

MÉTRAUX, A., 1932 - Mitos y cuentos de los indios chiriguano. Revista del Museo de La Plata, 33 (9): 119-184; La Plata.

NEEDHAM, R., 1972 - Belief, Language and Experience, 269 p.; Oxford: Basil Blackwell.

NEEDHAM, R. (ed.), 1973 - Right and Left. Essays in Dual Symbolic Classification, 449 p.; Chicago: The University of Chicago Press.

NORDENSKIÖLD, E., 2002 - La vida de los indios. El Gran Chaco (Sudamérica), 312 p.; La Paz: APCOB-Plural.

PALMER, J., 2005 - La buena voluntad wichí. Una espiritualidad indígena, 386 p.; Formosa/ Salta: FAPCD.

RENARD-CASEVITZ, F.-M., SAIGNES, T. \& TAYLOR, A. C., 1986 - L'Inca, I'Espagnol et les Sauvages. Rapports entre les sociétés amazoniennes et andines du XV au XVII siècle, 411 p.; París: Editions Recherche sur les Civilisations («Synthèse» $\mathrm{n}^{\circ} 21$ ).

RYLE, G., 1963 - The Concept of Mind, 316 p.; Middlesex: Penguin.

SAIGNES, T., 1990 - Ava y Karai: Ensayos sobre la frontera chiriguana (Siglos XVI-XX), 272 p.; La Paz: HISBOL. 
Algunos problemas de interpretación de la religión chané

SANTIAGO DE LEÓN, P., 1998 - Diccionario chiriguano-castellano y castellano-chiriguano, 172 p.; Tarija/Camiri: Centro Eclesial de Documentación, Teko Guaraní.

STEINER, F. B., 1999 - Taboo, Truth and Religion, 279 p.; Oxford: Berghahn.

STERPIN, A., 1993 - L'Espace social de la prise de scalps chez les Nivacle du Gran Chaco. Hacia una nueva carta étnica del Gran Chaco, 5: 129-192; Las Lomitas, Argentina.

SURRALLÉS, A., 2003 - Face to face: Meaning, Feeling and Perception in Amazonian Welcoming Ceremonies. Journal of the Royal Anthropological Institute (n.s.), 9: 775791; Londres.

SUSNIK, B., 1968 - Chiriguanos I. Dimensiones etnosociales, 269 p.; Asunción: Museo Etnográfico Andrés Barbero.

TAYLOR, A. C., 1996 - The soul's body and its states: An amazonian perspective on the nature of being human. Journal of the Royal Anthropological Institute (n.s.), 2: 201215; Londres.

VERNANT, J. P., 1994 - Mito y sociedad en la Grecia antigua, 220 p.; Madrid: Siglo XXI.

VILLAR, D., 2005 - Indios, blancos y perros. Anthropos, 100 (2): 495-506; Sankt Augustin.

VILLAR, D., 2006 - La religión chané. Tesis de Doctorado en Filosofía y Letras, Universidad de Buenos Aires, 243 p.

VIVEIROS DE CASTRO, E., 1998 - Cosmological Deixis and Amerindian Perspectivism. Journal of the Royal Anthropological Institute (n.s.), 4: 469-488; Londres.

VIVEIROS DE CASTRO, E., 1992 - From the Enemy's Point of View. Humanity and Divinity in an Amazonian Society, 406 p.; Chicago: The University of Chicago Press. 